\title{
Is it worth treating gestational diabetes: if so, when and how?
}

\author{
Marja Vääräsmäki ${ }^{1}$
}

Received: 18 January 2016 / Accepted: 30 March 2016 / Published online: 11 May 2016

(C) Springer-Verlag Berlin Heidelberg 2016

\begin{abstract}
The primary aims of the treatment of gestational diabetes (GDM) are to prevent macrosomia and pregnancy complications. Many large studies and meta-analyses have demonstrated that, compared with usual care, the specific treatment of women with GDM seems to achieve these aims, including lower birthweight and lower rates of shoulder dystocia. Nutritional therapy is a cornerstone of GDM care and is generally recommended as a primary treatment. Medical treatment should be started after 1-2 weeks if normoglycaemia is not achieved with lifestyle changes. This review provides an overview of the current data on and practices for the treatment of GDM and summarises a presentation given at the 'Gestational diabetes: what's up?' symposium at the 2015 annual meeting of the EASD. It is accompanied by two other reviews on topics from this symposium (by Peter Damm and Colleagues, DOI: 10.1007/s00125016-3985-5, and by Cuilin Zhang and colleagues, DOI: 10 . 1007/s00125-016-3979-3) and an overview by the Session Chair, Kerstin Berntorp (DOI: 10.1007/s00125-016-3975-7).
\end{abstract}

Keywords Gestational diabetes · Glibenglamide · Glycaemic control $\cdot$ Insulin $\cdot$ Large-for-gestational-age $\cdot$ Macrosomia · Medical treatment $\cdot$ Metformin $\cdot$ Nutritional therapy $\cdot$ Pregnancy complications $\cdot$ Review

\section{Abbreviations \\ GDM Gestational diabetes \\ LGA Large-for-gestational-age}

Marja Vääräsmäki

marja.vaarasmaki@oulu.fi

1 PEDEGO Research Unit (Research Unit for Pediatrics, Dermatology, Clinical Genetics, Obstetrics and Gynecology), Medical Research Center Oulu (MRC Oulu), Oulu University hospital and University of Oulu, PO Box 23, 90029, OYS Oulu, Finland
NNT Number needed to treat

RCT Randomised clinical trial

Gestational diabetes (GDM) is the most common type of diabetes affecting pregnancy. Its incidence is increasing fast, and today, up to $14 \%$ of pregnant women worldwide are diagnosed with GDM [1]. Because of this high prevalence, in addition to screening for and diagnosing GDM, its treatment must be well validated and worthwhile in terms of cost vs benefit.

\section{Risks associated with GDM}

The well-known maternal short-term risks associated with GDM include increased rates of gestational hypertension and pre-eclampsia, and an increased frequency of Caesarean sections [2-4]. Fetal overgrowth, i.e. macrosomia, is the most significant risk for the fetus as it is associated with an increased risk of shoulder dystocia and neonatal hypoglycaemia $[5,6]$. In the long term, women with a history of GDM have been found to be at an increased risk of type 2 diabetes, the metabolic syndrome and other cardiovascular diseases [7-10]. Concerning the child, recent studies have reported increased risks of obesity and other metabolic disorders [11-13]. However, it is not evident whether these longterm risks can be prevented by intensive treatment of GDM, nor is it clear what role intrauterine exposure, genetic factors or postnatal environment may play in the health of the child.

\section{Is GDM worth treating?}

The primary goal of the treatment of GDM is to prevent macrosomia and pregnancy complications [14]. Two large randomised controlled studies compared usual prenatal care with intensive treatment of women with GDM. In an 
Australian study, 1,000 women with GDM were randomised to receive routine care (control) or lifestyle advice supplemented with insulin if necessary [15]. The intervention group showed a significant decrease, from $4 \%$ to $1 \%$, of composite measures of serious perinatal complications, including death, shoulder dystocia, bone fracture and nerve palsy. The number needed to treat (NNT) to prevent one serious outcome was 34 and, therefore, the treatment can be considered worthwhile. There were no differences in Caesarean delivery rates between the study groups, but a greater number of labours were induced and more infants were admitted to the neonatal nursery, which may also reflect physicians' awareness of mothers' diagnoses.

The results of another large randomised controlled trial were published 4 years later [16]. In this US study, 485 mothers received the intervention and there were 473 controls. The composite outcome included perinatal mortality, birth trauma and maternal hyperglycaemia-related states such as neonatal hypoglycaemia, hyperbilirubinaemia or hyperinsulinaemia defined by C-peptide and did not differ significantly between the intervention and control groups. In contrast, in terms of secondary outcomes, both of these large studies $[15,16]$ reported significant decreases in the proportion of offspring with macrosomia (defined by the amount of largefor-gestational-age [LGA] newborns), actual birthweight, and birthweight $>4 \mathrm{~kg}$. In the latter study, the pre-eclampsia rate and maternal weight gain during pregnancy were lower in intensively treated women. Subsequent meta-analyses have concluded that intensive treatment of GDM is associated with reduced risks of macrosomia, LGA and shoulder dystocia [17, 18]. In their systematic review, Falavigna et al noted that the NNT to prevent one case of macrosomia was 11 , and 12 to prevent one case of LGA [19]. Active treatment was not found to cause any harm for mothers or their newborns but imposed an increased demand for healthcare services [18].

Intensive counselling during pregnancy may educate women to make better subsequent lifestyle choices, and it may also help to improve their quality of life, but studies in this area are scarce. In one follow-up study, maternal depression rates 3 months after delivery were lower in the intervention group than in the group of mothers who received usual care [15]. Though the intensive treatment of mothers with GDM was associated with a significant decrease in birthweight and macrosomia, it was not found to result in a change in the child's BMI at age 4-5 [20] or in a reduction of childhood obesity or metabolic dysfunction at age 5-10 [21] in the follow-ups of the previously mentioned studies. Hence, longer follow-up studies are merited.

\section{Timing of the treatment}

Given that GDM is typically diagnosed at the beginning of the last trimester, there is little time for lifestyle education and intensive treatment. In the aforementioned randomised studies, treatment began, on average, at week 29 of gestation, yet it still had beneficial effects $[15,16]$. While the treatment should be initiated as soon as GDM is diagnosed, earlier initiation of treatment for mild GDM has not been associated with greater beneficial effects on perinatal outcomes [22].

\section{Treatment of hyperglycaemia and follow-up}

When the treatment of GDM appears justified, how should it be put into practice? Nutritional therapy is a cornerstone of GDM care and is generally recommended as a primary treatment. It should be planned to maintain sufficient energy intake and to ensure glycaemic control of the mother. An optimal diet together with physical activity to improve insulin sensitivity prevents excessive maternal and fetal weight gain and reduces the need for medical treatment. This regimen has been found to be sufficient in $70-85 \%$ of cases [23]. While there are no specific guidelines for diet or exercise regarding women with GDM, the aim of this primary treatment is to maintain euglycaemia and prevent excess weight gain. A recent meta-analysis found that a diet with a low glycaemic index is associated with less frequent insulin use and lower birthweights than control diets [24], but these findings have yet to be replicated. Medical treatment is commonly recommended if blood glucose targets are not met within $1-2$ weeks after changes in diet and exercise $[25,26]$.

GDM patients are conventionally asked to measure their blood glucose values before breakfast and $1-2 \mathrm{~h}$ after meals, although the optimal timing and frequency of measurements is somewhat ambiguous. Moreover, glucose targets vary in different studies. The most frequently recommended target concentrations are $<5.5 \mathrm{mmol} / 1$ for fasting plasma glucose, $<7.8 \mathrm{mmol} / \mathrm{l}$ for $1 \mathrm{~h}$ postprandial glucose and $<6.7 \mathrm{mmol} / \mathrm{l}$ for $2 \mathrm{~h}$ postprandial glucose [27]. Both preprandial and postprandial glycaemia appear to be important, and lower values are often associated with lower complication rates [28].

\section{Medical treatment of GDM}

Traditionally, insulin has been the primary medical treatment if maternal normoglycaemia is not achieved via nutritional therapy. Insulin is still recommended as the first-line pharmacological therapy by many guidelines. It is effective and safe for the fetus, as it does not cross the placenta; yet, it is costly, and its use requires training and education, particularly because of the related risk of hypoglycaemia. Insulin treatment also increases appetite and weight gain [29]. According to the current evidence, all types of insulin can be used to treat GDM if normoglycaemia is not achieved with the help of lifestyle counselling. Often, the costs of different 
preparations affect the choice of insulin. The principles for insulin dosing in GDM do not differ from those in type 1 or type 2 diabetes [29].

Regarding oral glucose-lowering agents, metformin and glibenclamide have been used and studied in the treatment of GDM. The other oral agents have limited or no human data available regarding their use during pregnancy. Glibenclamide belongs to the class of glucose-lowering medications called sulfonylureas, which act by increasing insulin secretion from the pancreatic beta cells. The first large randomised clinical trial (RCT) comparing glibenclamide and insulin in the treatment of GDM was published by Langer et al in 2000 [30]. According to the study, glibenclamide proved a promising alternative to insulin: only $4 \%$ of the glibenclamide-treated patients needed additional insulin; maternal hypoglycaemia was infrequent and glycaemic control and perinatal outcomes did not differ between the study groups. Moreover, glibenclamide was not detected in the cord serum of the newborn. However, in a clinical study, the concentration of glibenclamide in the umbilical cord was reported to be around $70 \%$ that in the maternal blood, indicating that it crosses the placenta [31]. There are currently no data on its use during the first trimester or any follow-up studies of children who have been exposed to glibenclamide antenatally.

Metformin was first used during pregnancy to treat type 2 diabetes $[32,33]$ and thereafter the main context of its use during pregnancy largely consisted of studies that included women with polycystic ovary syndrome [34, 35]. Recently, several RCTs have compared metformin and insulin as a treatment of GDM [36-42]. According to these RCTs, metformin seems to be comparable to insulin as regards glycaemic control and neonatal outcomes, while being associated with less maternal weight gain and lower rates of neonatal hypoglycaemia and, possibly, gestational hypertension. However, in some studies, it has been associated with an increased rate of premature births [43].

The benefits of metformin treatment during pregnancy include no risk of hypoglycaemia or excessive maternal weight gain. Moreover, it is low cost and easy to use. However, it may cause gastrointestinal symptoms and, although rare, there is a risk of lactic acidosis. Since it passes through the placenta, it may have effects on the child. According to recent studies, metformin appears to be safe for the fetus and newborn, yet its possible long-term effects are not yet known. In addition, euglycaemia is not always achieved with metformin, and supplemental insulin has been necessary in $34 \%$ of cases [44]. Treatment failures are associated with severe cases of GDM defined by early GDM diagnosis and need for medication, maternal obesity, high fasting glucose numbers and prior GDM [43, 44].

While both glibenclamide and metformin cross the placenta, their long-term effects on the child have yet to be considered. To date, there are follow-up studies only on metformin in GDM treatment, and these data are accumulating little by little. Until now, offspring exposed to metformin have been found to have more favourable fat distribution, and similar blood pressure at the age of 2 years compared with offspring in the insulin group $[45,46]$. One study found no differences in motor, social or linguistic development at 18 months of age [47]. In the same study, the degree of adiposity was similar in both the metformin and insulin groups, but children exposed to metformin antenatally were heavier at the age of 12 months and both taller and heavier at the age of 18 months [47].

\section{Comparison of medications and guidelines for medical treatment}

A meta-analysis of six studies of GDM patients on metformin, glibenclamide and insulin reported no differences between the groups in terms of maternal fasting and postprandial glycaemic control [48]. When oral glucose-lowering agents were compared with insulin, they were not associated with increased rates of neonatal hypoglycaemia, birthweight, LGA babies or Caesarean deliveries.

A recent meta-analysis compared insulin, glibenclamide and metformin for the treatment of GDM [44]. Compared with insulin, glibenclamide was associated with higher birthweight and higher rates of macrosomia and neonatal hypoglycaemia. Compared with metformin, glibenclamide was associated with more maternal weight gain, higher birthweight and higher rates of macrosomia and LGA. The authors concluded that glibenclamide should not be used if metformin or insulin is available.

The recommendations of offically recognised guidelines are not unanimous regarding the medical treatment of GDM. The American Diabetes Association (ADA), Canadian Diabetes Association (CDA) and International Diabetes Federation (IDF) prefer insulin as the first-line pharmacological treatment, whereas the UK National Institute for Health and Care Excellence (NICE) recommends metformin as the first-line treatment, and insulin only in severe cases. The American College of Obstetricians and Gynecologists (ACOG) considers insulin and oral agents equally efficacious for first-line treatment [29].

\section{Is GDM worth treating?}

The primary aims of the treatment of GDM are to prevent macrosomia and pregnancy complications. Many large studies and meta-analyses have demonstrated that, compared with usual care, the specific treatment of women with GDM has significant beneficial effects, including lower birthweight and lower rates of shoulder dystocia, and is likely to lower the 
proportion of hypertensive complications. Hence, treatment seems to meet the target. It is also possible and desirable that intensive counselling during pregnancy may educate women to make better lifestyle choices, which would in turn benefit the whole family.

Medical treatment should be initiated if normoglycaemia is not achieved within 1-2 weeks after lifestyle changes are implemented. While insulin is widely accepted as the firstline option, the treatment is demanding and expensive. However, in severe cases, use of insulin is justified to quickly reach and maintain glycaemic targets. Out of the possible oral glucose-lowering agents, metformin is preferable to glibenclamide because of its favourable effect profile and the fact that it is associated with less maternal weight gain and less macrosomia compared with glibenclamide. However, metformin is not always sufficient. Indeed, every third woman needs supplemental insulin to reach normoglycaemia. In these severe cases, concurrent treatment with both medications might be a rational alternative. If long-term results indicate no adverse effects on children who have antenatal exposure to metformin, then oral therapy might be considered the firstline medication for GDM patients.

Duality of interest The author declares that there is no duality of interest associated with this manuscript.

Contribution statement The author was the sole contributor to this paper.

\section{References}

1. American Diabetes Association (ADA) (2007) Diagnosis and classification of diabetes mellitus. Diabetes Care 30:S42-S47

2. Suhonen L, Teramo K (1993) Hypertension and pre-eclampsia in women with gestational glucose intolerance. Acta Obstet Gynecol Scand 72:269-272

3. Schmidt MI, Duncan BB, Reichelt AJ et al (2001) Gestational diabetes mellitus diagnosed with a 2-h 75-g oral glucose tolerance test and adverse pregnancy outcomes. Diabetes Care 24:1151-1155

4. HAPO Study Cooperative Research Group (2010) Hyperglycaemia and Adverse Pregnancy Outcome (HAPO) Study: associations with maternal body mass index. BJOG 117:575-584

5. HAPO Study Cooperative Research Group (2008) Hyperglycemia and adverse pregnancy outcomes. N Engl J Med 358:1991-2002

6. Reece EA (2010) The fetal and maternal consequences of gestational diabetes mellitus. J Matern Fetal Neonatal Med 23:199-203

7. Lauenborg J, Hansen T, Jensen DM et al (2004) Increasing incidence of diabetes after gestational diabetes: a long-term follow-up in a Danish population. Diabetes Care 27:1194-1199

8. Bellamy L, Casas JP, Hingorani AD, Williams D (2009) Type 2 diabetes mellitus after gestational diabetes: a systematic review and meta-analysis. Lancet 373:1773-1779

9. Retnakaran R, Shah BR (2009) Mild glucose intolerance in pregnancy and risk of cardiovascular disease: a population-based cohort study. CMAJ 181:371-376
10. Ijäs H, Morin-Papunen L, Keränen AK et al (2013) Pre-pregnancy overweight overtakes gestational diabetes as a risk factor for subsequent metabolic syndrome. Eur J Endocrinol 169:605-611

11. Boney CM, Verma A, Tucker R, Vohr BR (2005) Metabolic syndrome in childhood: association with birth weight, maternal obesity, and gestational diabetes mellitus. Pediatrics 115:290-296

12. Catalano PM, Farrell K, Thomas A et al (2009) Perinatal risk factors for childhood obesity and metabolic dysregulation. Am J Clin Nutr 90:1303-1313

13. Vääräsmäki M, Pouta A, Elliot P et al (2009) Adolescent manifestations of metabolic syndrome among children born to women with gestational diabetes in a general-population birth cohort. Am J Epidemiol 169:1209-1215

14. Evensen AE (2012) Update on gestational diabetes mellitus. Prim Care 39:83-94

15. Crowther CA, Hiller JE, Moss JR et al (2005) (2005) Effect of treatment of gestational diabetes mellitus on pregnancy outcomes. N Engl J Med 352:2477-2486

16. Landon MB, Spong CY, Thom E et al (2009) A multicenter, randomized trial of treatment for mild gestational diabetes. N Engl J Med 361:1339-1348

17. Horvath K, Koch K, Jeitler K et al (2010) Effects of treatment in women with gestational diabetes mellitus: systematic review and meta-analysis. BMJ 340:1395

18. Hartling L, Dryden DM, Guthrie A, Muise M, Vandermeer B, Donovan L (2013) Benefits and harms of treating gestational diabetes mellitus: a systematic review and meta-analysis for the U.S. Preventive Services Task Force and the National Institutes of Health Office of Medical Applications of Research. Ann Intern Med 159:123-129

19. Falavigna M, Schmidt MI, Trujillo J et al (2012) Effectiveness of gestational diabetes treatment: a systematic review with quality of evidence assessment. Diabetes Res Clin Pract 98:396-405

20. Gillman MW, Oakey H, Baghurst PA, Volkmer RE, Robinson JS, Crowther CA (2010) Effect of treatment of gestational diabetes mellitus on obesity in the next generation. Diabetes Care 33: 964-968

21. Landon MB, Rice MM, Varner MW et al (2015) Mild gestational diabetes mellitus and long-term child health. Diabetes Care 38: 445-452

22. Palatnik A, Mele L, Landon MB et al (2015) Timing of treatment initiation for mild gestational diabetes mellitus and perinatal outcomes. Am J Obstet Gynecol 213:560.e1-560.e8

23. Association AD (2016) 12. Management of diabetes in pregnancy. Diabetes Care 39(Suppl 1):S94-S98

24. Viana LV, Gross JL, Azevedo MJ (2014) Dietary intervention in patients with gestational diabetes mellitus: a systematic review and meta-analysis of randomized clinical trials on maternal and newborn outcomes. Diabetes Care 37:3345-3355

25. NICE Guideline (2015) Diabetes and pregnancy: management of diabetes and its complications from preconception to the postnatal period. Available from www.nice.org.uk/guidance/ng3/resources/ diabetes-in-pregnancy-management-of-diabetes-and-itscomplications-from-preconception-to-the-postnatal-period51038446021, accessed 30 December 2015

26. International Diabetes Federation (2009) Global guideline on pregnancy and diabetes. IDF, Brussels Available from www.idf. org/webdata/docs/Pregnancy_EN_RTP.pdf, accessed 30 December 2015

27. Metzger BE, Buchanan TA, Coustan DR et al (2007) Summary and recommendations of the Fifth International Workshop-Conference on Gestational Diabetes Mellitus. Diabetes Care 30(Suppl 2): S251-S260

28. Rowan JA, Gao W, Hague WM, McIntyre HD (2010) Glycemia and its relationship to outcomes in the metformin in gestational diabetes trial. Diabetes Care 33:9-16 
29. Kelley KW, Carroll DG, Meyer A (2015) A review of current treatment strategies for gestational diabetes mellitus. Drugs Context 4: 212282

30. Langer O, Conway DL, Berkus MD, Xenakis EM, Gonzales O (2000) A comparison of glyburide and insulin in women with gestational diabetes mellitus. N Engl J Med 343:1134-1138

31. Hebert MF, Ma X, Naraharisetti SB et al (2009) Are we optimizing gestational diabetes treatment with glyburide? The pharmacologic basis for better clinical practice. Clin Pharmacol Ther 85:607-614

32. Coetzee EJ, Jackson WP (1984) Oral hypoglycaemics in the first trimester and fetal outcome. S Afr Med J 65:635-637

33. Coetzee EJ, Jackson WP (1979) Metformin in management of pregnant insulin-independent diabetics. Diabetologia 16:241-245

34. Velazquez EM, Mendoza S, Hamer T, Sosa F, Glueck CJ (1994) Metformin therapy in polycystic ovary syndrome reduces hyperinsulinemia, insulin resistance, hyperandrogenemia, and systolic blood pressure, while facilitating normal menses and pregnancy. Metabolism 43:647-654

35. Vanky E, Stridsklev S, Heimstad R et al (2010) Metformin versus placebo from first trimester to delivery in polycystic ovary syndrome: a randomized, controlled multicenter study. J Clin Endocrinol Metab 95:E448-E455

36. Moore LE, Briery CM, Clokey D et al (2007) Metformin and insulin in the management of gestational diabetes mellitus: preliminary results of a comparison. J Reprod Med 52:1011-1015

37. Rowan JA, Hague WM, Gao W, Battin MR, Moore MP, Investigators MGT (2008) Metformin versus insulin for the treatment of gestational diabetes. N Engl J Med 358:2003-2015

38. Ijäs H, Väärasmäki M, Morin-Papunen L et al (2010) Metformin should be considered in the treatment of gestational diabetes: a prospective randomised study. BJOG 118:880-885

39. Niromanesh S, Alavi A, Sharbaf FR, Amjadi N, Moosavi S, Akbari S (2012) Metformin compared with insulin in the management of gestational diabetes mellitus: a randomized clinical trial. Diabetes Res Clin Pract 98:422-429
40. Mesdaghinia E, Samimi M, Homaei Z, Saberi F, Moosavi SG, Yaribakht M (2013) Comparison of newborn outcomes in women with gestational diabetes mellitus treated with metformin or insulin: a randomised blinded trial. Int J Prev 4:327-333

41. Spaulonci CP, Bernardes LS, Trindade TC, Zugaib M, Francisco RP (2013) Randomized trial of metformin vs insulin in the management of gestational diabetes. Am J Obstet Gynecol 209: 34.e1-34.e7

42. Tertti K, Ekblad U, Koskinen P, Vahlberg T, Ronnemaa T (2013) Metformin vs. insulin in gestational diabetes. A randomized study characterizing metformin patients needing additional insulin. Diabetes Obes Metab 15:246-251

43. Gui J, Liu Q, Feng L (2013) Metformin vs insulin in the management of gestational diabetes: a meta-analysis. PLoS One 8:e64585

44. Balsells M, Garcia-Patterson A, Sola I, Roque M, Gich I, Corcoy R (2015) Glibenclamide, metformin, and insulin for the treatment of gestational diabetes: a systematic review and meta-analysis. BMJ 350:h102

45. Rowan JA, Rush EC, Obolonkin V, Battin M, Wouldes T, Hague WM (2011) Metformin in gestational diabetes: the offspring follow-up (MiG TOFU): body composition at 2 years of age. Diabetes Care 34:2279-2284

46. Battin MR, Obolonkin V, Rush E, Hague W, Coat S, Rowan J (2015) Blood pressure measurement at two years in offspring of women randomized to a trial of metformin for GDM: follow up data from the MiG trial. BMC Pediatr 15:54

47. Ijäs H, Vääräsmäki M, Saarela T, Keravuo R, Raudaskoski T (2015) A follow-up of a randomised study of metformin and insulin in gestational diabetes mellitus: growth and development of the children at the age of 18 months. BJOG 122:994-1000

48. Dhulkotia JS, Ola B, Fraser R, Farrell T (2010) Oral hypoglycaemic agents vs insulin in management of gestational diabetes: a systematic review and metaanalysis. Am J Obstet Gynecol 203: 457.e1-457.e9 